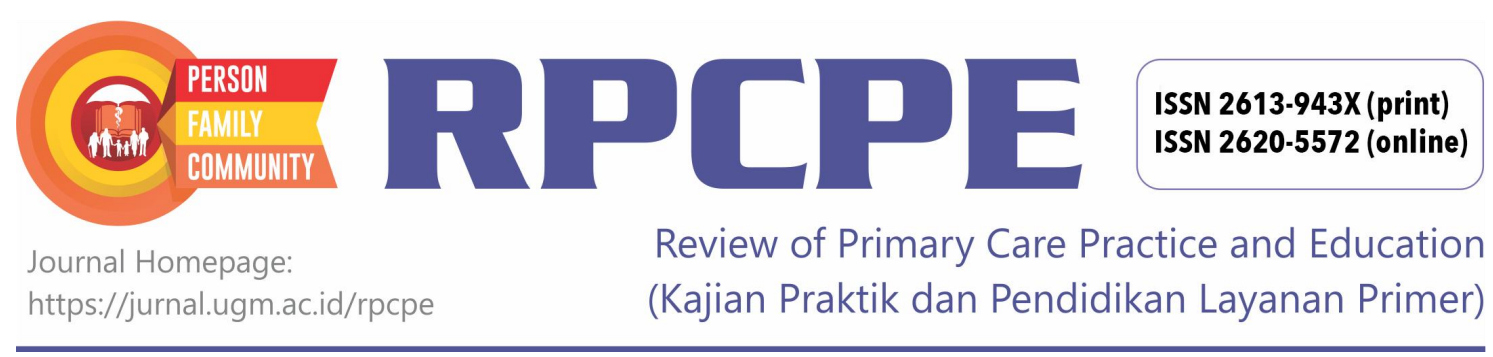

\title{
Idea on the Clinical Services of Primary Care Physicians
}

\author{
Adi Heru Sutomo ${ }^{1}$, Fitriana ${ }^{1}$
}

\author{
${ }^{1}$ Department of Family and Community Medicine; Faculty of Medicine, Public Health, and Nursing;Universitas Gadjah \\ Mada; Indonesia
}

Corresponding Author:

Adi Heru Sutomo: Department of Family and Community Medicine; Faculty of Medicine, Public Health, and Nursing; Universitas Gadjah Mada. Gd. Radiopoetro, Lt. 1 Sayap Barat, Jl. Farmako Sekip Utara, Yogyakarta - 55281, Indonesia Email: adiheruhusodo@gmail.com

To cite this article:

Sutomo AH, Fitriana. Idea on the clinical services of primary care physicians. Rev Prim Care Prac and Educ. 2018; 1(3): 99-102.

\section{BACKGROUND}

The increasing needs and health problems that exist in the community and the more critical the community-related health problems that require the ability of a primary care doctor able to handle existing health problems in the community. Primary care doctor complies with Alma Ata Declaration in 1978 as the backbone of health that makes direct contact with the community, so it is essential for a primary care doctor to involve the patient or the patient as part of the team. Patient experience information or patients given to primary care doctors is expected to further improve the quality of patient health services as individuals and is part of the family and society or community.

For a primary doctor, the focus of healthcare is on clinical skills with an emphasis on prevention at the level of primary care, management of primary health care facilities and health management oriented to the community and society. That is the difference of primary care doctors from other clinicians in conventional public health.

\section{DISCUSSIONS}

In the era of Sustainable Development Goals (SDGs) to address various health problems, various healthcare concepts must be able to support health care systems, especially for universal health coverage era (UHC). In providing a health service, it is implemented by integrating community health care with individuals (FOME - Family Oriented Medical Education), which promotes promotions but does not reduce curative and rehabilitative approach by nine family functions. Referring to the Vision (an independent community for healthy living) and Mission (making the people healthy). So, the family doctor must have a role as a determinant of the achievement of service quality, adequate and fair financing. With the existence of a more comprehensive health approach to the family. Family doctors are doctors who are oriented to provide first-level health services that are continuous and comprehensive to the unity of individuals, families, communities by considering environmental, economic and socio-cultural factors. Such an approach is also carried out by primary care doctors. Primary service doctors are doctors who specialize professions in primary health care. Primary health care is a service where patients first contact with health workers when they have a complaint, which in the JKN (national health coverage) system is handled by firstlevel health facilities such as health centers, family doctors, clinics, etc. Primary care doctors also have additional competencies, namely health management centered on individuals and families, leadership, management of primary health care facilities, and health management oriented to the community and society.

In order to produce a primary care doctor, continuing education is needed to improve the quality of health services, improvements in health information systems and improvement of medical support systems, i.e., laboratories, care services, referrals, and emergency services. An education media can support the primary care doctors to improve the quality of patient care and safety, to improve the competence of human resources continuously under the development of science and technology of medicine, dentistry, and other health. It also helps the doctors to be able to meet the standard health care facilities and educational equipment following technological developments and community need based on their function and classification and to be able to run an effective, efficient, and accountable clinical practice. 
The function of primary care doctors is identical with family doctors in several aspects ${ }^{1}$ because:

\section{Patients are part of the family}

In various scientific fields, participation has many different definitions, the example in sociology, participation can explain with having a share in something, and benefiting from that share, or taking part in a group and thus collaborating with that group. In healthcare, investigation studies show that the focus of interest has been on participation. Patients are partners with health care providers, and providers can treat their patients not only from a clinical perspective, but also from an emotional, mental, spiritual, social, and financial perspective.

Many studies showed that patient participation in health care had been associated with treatment outcomes improving. The importance of patient participation in the decision-making process motivates the provider services and healthcare team in promoting patient's participation in making the treatment decision.

\section{COME}

Hamad said that community-oriented was the concept of primary health care in the health system approach and COME is an approach to medical education. COME is focused on population groups and individual persons considering the health needs of the community concerned $^{2}$.

Community medical education refers to medical education, which situated the learner's clinical training in a community setting. Primary care clinicians and other healthcare providers accept learners into their practice, that they take on the role of delivering much of the curriculum and precepting learners, such as student must follow the patient from office setting into hospital care and back home to the community.

There is a relationship between the community with clinicians and graded responsibility. In COME, particularly longitudinal experiences, medical students are embedded within a small group of clinicians with whom they work closely and come to know well as their professional community. The closest working relationships between learners and their clinical supervisors over time allow for the maturation of an apprenticeship relationship. Through COME, students judge to be safe and respectful of patients are often able to take on more clinical responsibilities sooner in a known, safe environment. A personal relationship between student and preceptor, which develops over time, can mature more rapidly in COME programs, where there are fewer health professionals working closely together and working relationships are more consistent than in most tertiary hospital settings. In COME, there is a mature of relationships between students and clinical preceptors, facilitating preceptor awareness of the clinical growth of their learner.

Students are taught and delegated tasks and can make a meaningfully contribute to the healthcare team. There is positive reinforcement for clinical supervisors through the effectiveness of clinical task performance by students. Through the continuity of supervision, students are likely receiving consistent instruction and feedback. This consistency of apprentice relationships enhances entrustment of professional activities, resulting in critical functional changes in the three-way relationship between the preceptor, student, and patient during the consultation as students moved from passive to active members of the clinical team.

Through COME, students are introduced to individual patients and to the community in which these patients live. Students are recognized as potential future workforce members and are welcomed into the town.

In the primary context, students can be given the opportunity of seeing patients on their own before the general practitioner joins the consultation. It can develop a relationship between students with individual patients and contribute to their care. Even in short COME, students still have opportunities following individual patients and contribute to their care. Learning from real setting with people with medical conditions who live within a student's own community, rather than about pathology in patients who are short-term residents in the tertiary hospital setting, is likely to prevent them losing empathy and objectifying patients, a common outcome in traditional clinical clerkships.

\section{FOME}

In providing a health service, it is implemented by integrating family-oriented health services that promote preventive-promotion, but does not reduce curative and rehabilitative, namely by approaching the nine family functions ${ }^{3}$.

The family approach is a process that develops the ability of the family to do and act on decisions based on information or knowledge regarding the caregiving to the members, by using its own resources or with the road accessing the other resource ${ }^{4}$.

Family empowerment is all efforts instructive nonfacilitation, to enhance the knowledge and ability of the family to identify problems, plan and perform troubleshooting, without or with the help of the other party, by utilizing the potential of the family and existing facilities of the community. Family empowerment especially directed at promotive and preventive efforts (Healthy Paradigm), without prejudice to curative and rehabilitative efforts ${ }^{4}$.

\section{The JKN era}

According to Akmal, health services include promotive, preventive, curative and rehabilitative with financing patterns that can control the increase in service costs, including prospective payments and tiered health services. This health service starts at a first level health facility. The direction of health services in the JKN era is described as follows 5 : 


\section{a. Health cost calculation}

Calculation of health care (medical cost/MC), an allocation of funds that will be used in the cost of healthcare benefits that suit, will be provided. The value of the $\mathrm{MC}$ is the allocation of the funds will be paid to the giver of health services (hospitals, clinics, doctors) which provides health guarantee package. The estimated cost of medical services is calculated with the number of probability (Dij) with a rate per service type $(\mathrm{Pj})$. Thus, the basic formula for calculating the cost of health services (j) by the individual (i) is as follows: health costs, $(\mathrm{MCij})=$ $[(\mathrm{Dij}) *(\mathrm{Pj})]^{6}$.

\section{b. Improving the quality of health services}

In the plan for the development of health services, revamping the types and development of health services must include the following aspects the development of facilities services Health, reference systems strengthening, the development facilities services Health and accreditation of medical service standard in order to maintain the quality of medical services, human resources development, the development of pharmaceutical and tool health, preparation of standardization of healthcare costs and tariffs and regulatory drafting related ${ }^{6}$.

\section{c. Quality of health administration}

Quality of administration can be improved with socialization by holding a particular forum involving relevant agencies such as the health facilities, government agencies, the improvement of information systems and coordination by involving The Ministry of Communications and Informatics, Ministry of Health, BPJS Ministry of health, Ministry of social, as well as service-service related in each region in the integration program, pursues the $\mathrm{JKN}^{7}$.

\section{d. Improved medical information system / Medical Record}

The Organization of the health information systems adapted to the framework of the national health system $^{8}$. It is necessary for the development and strengthening of health information systems were done by observing the following principles:

1. The utilization of Information and Communication Technology (ICT) systems necessary to support the information in the process of recording data in order to improve the accuracy of data and speed in the provision of data for the dissemination of information and to improve the efficiency in the working process and strengthen the transparency.

2. Health information systems are developed can guarantee the security and confidentiality of the data.

3. In order to standardized health information systems, need to provide guidelines for the development and utilization of ICT.

4. Health information systems are developed can integrate a wide range of data sources, including in the utilization of ICT.
5. The data and information available are easily accessible by all stakeholders.

6. The data and information collected should be able to be traced individually and more in the aggregate, so that they can describe the differences in gender, economic status social, and geography.

7. The Organization of the health information systems should also pay attention to the principle of ethics, integrity, and quality ${ }^{8}$.

\section{e. Improvement of medical support system, for} example:
i. Laboratory
ii. Care
iii. Reference
iv. Transportation
v. Emergency
vi. Etc.

From the explanation above, in the Primary Services Clinic or DLP Clinic should include the facilities and services to improve primary care units such as:

\section{Medical Clinic}

The Medical Clinic includes:

a. Patient examination room

b. Pharmacies

c. Consultation Room ${ }^{9}$ :
1. Nutrition
2. Mental Medicine
3. Family Genetics (Genogram)
4. Etc.

d. Medical Support Room:

1. Microbiology Laboratory

2. Lab. Parasitology

3. Lab. Clinical Pathology

4. Lab. Anatomical Pathology

5. Etc.

e. Referral System / Referral

1. Transportation

2. Medical Information System

f. Office Administration

When listening to the article about the medical clinic above, it is apparent that the facilities for the medical clinic should be as complete as possible, which includes patient examination room, consultation room, pharmacy, medical support room, referral room and office administration.

\section{Non-Medical Clinic}

Non-Medical Clinic includes:

The non-medical clinic covers non-medical matters or public health, i.e.

a. Sanitation Clinic

b. Community Nutrition Clinic

c. Community Mental Health Clinic / Psychology

d. Healthcare Clinic

e. Health Promotion Clinic

f. First Aid Clinic in Accident (PPPK)

g. Health Support Laboratory:

1. Environmental Health Laboratory: a. Lab. Environmental Microbiology 
b. Lab. Environmental Parasitology

c. Lab. Community Nutrition

d. Lab. Environmental Pathology

2. Social Pathology Laboratory

3. Etc.

h. Home Visit Service, which includes:

1. Communication

2. Transportation

3. Health Information System

4. Etc.

The non-medical clinic covers things that are outside the medical system that is, in fact, necessary for the improvement of the public health status that should be in line with the results of the evaluations that have been implemented for health services ${ }^{10}$.

\section{CONCLUSION}

The idea of a Primary Care Clinic or Family Clinic mentioned above still needs to be refined in the hope that cases in primary care or within the family can be handled better.

\section{REFERENCES}

1. Ministry of Health Republic of Indonesia. Primary Doctor for Healthy Prosperous of Indonesia. Jakarta: Ministry of Health RI, 2017.

2. Hamad B. Community oriented medical education: What is it? Medical Education. 1991 Jan;25(1):16-22.

3. McDaniel SH, Campbell TL, Hepworth J, Lorenz A. Family-oriented primary care. Springer Science \& Business Media. 2005 Dec 6.

4. Central Java Provincial Health Office. Case Analysis Guide Through Family Approach. Semarang: Central Java Provincial Health Office. 2004.

5. Hendriyana A. In the JKN Era, there must be an increase in the quality of primary health services [Internet]. Unpad. 2013 [Accessed on 12 September 2018]. Available from: http:/www.unpad.ac.id/2013/12/di-era-jkn-ha- rus-ada-peningkatkualitas-pelayanan-kesehatan-primer/.

6. The Road to National Health Insurance. Jakarta: National Team for Accelerating Poverty Reduction. 2015.

7. Siamunisa H, Yeremias Tk. Analysis of the Quality of Public Services (Case Study of Membership Administration Services in Semarang City Health Office) [Doctoral dissertation]. Yogyakarta: Gadjah MadaUniversity.

8. Ministry of Health Republic of Indonesia. Regulation of the Minister of Health of the Republic of Indonesia Number: 97 Year 2014 concerning Road Map of the Health Information System Year 2015-2019. Jakarta: Ministry of Health Republic of Indonesia. 2014.

9. Graber MA, Wilbur J, Soldat L. Palliative Care and Bioethics in Primary Care, Editor Gayatri, Aghnaa; Claramita, Mora \& Sutomo, Adi Heru. Yogyakarta: Faculty of Medicine Gadjah Mada University, 2015.

10. DRD DIY 2017-2022. Strategic Policy and Research Agenda of the Special Region of Yogyakarta 2017-2022. Yogyakarta: Secretariat of the Development Administration Bureau, Regional Secretariat of the Special Region of Yogyakarta. 2017. 